\title{
The influence of perceptual information on control processes involved in self-regulated learning: evidence from item selection
}

\author{
Fengying Li • Ruibo Xie • Xinyu Li • Weijian Li
}

Published online: 21 November 2014

(C) Psychonomic Society, Inc. 2014

\begin{abstract}
Previous research has shown that perceptual information such as font size has an impact on learners' judgments of their own learning. The present study extended the font-size effect to examine the influence of font size on how people decide which items to study first. Across three experiments, we showed that participants preferred to first select items presented in a large font size ( $48 \mathrm{pt})$ more than items presented in a small font size (18 pt), and that this effect continued even when more diagnostic cues (difficulty and reward value of items) were presented, suggesting that perceptual cues can strongly influence control process involved in self-regulated learning. These results provide evidence that perceptual information plays a key role in higher cognition. Moreover, our results also suggest that control processes are influenced by multiple cues, including font size, difficulty of items, and the reward value of items.
\end{abstract}

Keywords Self-regulated learning · Item selection · Perceptual cue

\section{Introduction}

Perceptual information is increasingly recognized as being involved in high level cognition, including memory, concept processing, language comprehension (e.g., Kleider \& Goldinger, 2004; Wu \& Barsalou, 2009; see also Barsalou, 2010, for a review), and even in metacognition (e.g., Alban \& Kelley, 2013; Foster \& Sahakyan, 2012; Rhodes \& Castel, 2008, 2009). The present research focuses on one of these high level skills - metacognition, in which individuals

F. Li $\cdot$ R. Xie $\cdot$ X. Li $\cdot$ W. Li $(\bowtie)$

Department of Psychology, Zhejiang Normal University, Yingbin

Road 688, Jinhua 321004, Zhejiang Province, China

e-mail: xlxh@zjnu.cn monitor and control their own cognition (e.g., Nelson \& Narens, 1994), and hence, play a key role in self-regulated learning (Metcalfe, 2009). Although previous studies (e.g., Alban \& Kelley, 2013; Foster \& Sahkayan, 2012; Rhodes \& Castel, 2008) have provided evidence of influence of perceptual properties on monitoring of learning, little is known about the influence of perceptual properties on control of learning. Investigation of perceptual information on control process can contribute to our understanding of how people regulate their own learning and could potentially provide strong evidence supporting the idea that perceptual information plays a key role in higher cognition.

In a widely cited study, Rhodes and Castel (2008) examined the influence of font size on monitoring, in particular, on judgments of learning (JOLs), which tap learners' predictions about the likelihood of remembering the acquired information on an upcoming test (Koriat, 1997). They had participants study words presented in either large (48 pt) or small font (18 pt) and made JOLs for each word. The results showed that participants consistently gave higher JOLs for large words than they did for small words. More importantly, the font size exerted an influence on JOLs even when other diagnostic cues (e.g., relatedness of word pairs) were available, suggesting that people use perceptual cues to guide their monitoring. This font-size effect has been further confirmed by subsequent studies (e.g., Kornell, Rhodes, Castel, \& Tauber, 2011; Miele, Finn, \& Molden, 2011; Mueller, Dunlosky, Tauber, \& Rhodes, 2014; Susser, Mulligan \& Besken, 2013).

The above studies have provided strong evidence for the influence of perceptual information on monitoring. However, very few studies have investigated the influence of perceptual information on control (Miele \& Molden, 2010; Mueller et al., 2014; Rhodes \& Castel, 2009; Soderstrom \& Rhodes, 2014). Rhodes and Castel (2009, Experiment 2) had participants listen to words presented at different volumes (loud vs. quiet) and make a restudy choice (i.e., decide whether or not to 
restudy each item at a later time). The results showed that participants chose to restudy quiet words more than loud words, which was replicated by Soderstrom and Rhodes (2014, Experiment 2). The researchers explained this finding as perhaps being due to participants regarding quiet items as more difficult to learn, relative to loud items. Moreover, Miele and Molden (2010, Experiment 3) found that clarity of items impacted self-paced study times: participants spent more time on reading the text presented in an unclear font than those presented in a clear font. They also found that participants provided lower ratings of comprehension for the text in the unclear font, suggesting that the participant regarded the unclear-font text as more difficult to learn. These studies suggest that participants are likely to seek more study time or additional study on items that are subjectively difficult to process at a perceptual level (but see Mueller et al., 2014 for evidence that perceptual information does not necessarily affect study time), providing evidence that perceptual information might influence control process.

In addition to restudy choice and self-paced study time, another important measure of control process is the item selection when people are trying to learn new material (e.g., Dunlosky \& Ariel, 2011). How learners decide which items to study first exemplifies the order of priority of items chosen and taps the control process of self-paced study, which is one of the questions that has dominated research on self-regulated learning for several decades (Dunlosky \& Ariel, 2011). The focus of the current study is to examine whether perceptual information has an impact on learners' first item selection. Since font size is an important perceptual cue to convey information (see detailed description in Rhodes \& Castel, 2008), we asked whether font size is a basis for learners' first item selection. Previous studies have shown that participants regarded large words as more memorable than small words (e.g., Kornell et al, 2011; Rhodes \& Castel, 2008), suggesting that large items are easier to learn. According to a famous model of study time allocation - the discrepancy reduction model (DRM), which posits that learners focus on more difficult items to reduce the discrepancy between the current state of learning and their overall goal (e.g., Dunlosky \& Hertzog, 1998; Thiede \& Dunlosky, 1999)—one might predict that participants would first choose to study the small items. In contrast, the region of proximal learning (RPL) framework posits that people seek items that provide the highest rate of learning (e.g., the proportion recalled per second spent studying). Consistent with this possibility, there is evidence that time spent on the easy items resulted in more gain than did time spent on difficult items (Metcalfe \& Kornell, 2003). Thus, the RPL framework predicts that people prefer to study the easier items first. Accordingly, one might predict that participants would first choose to study the large items. In three experiments, we manipulated the font size of study items to explore whether people first chose large or small items for study. In order to test the robustness of the font-size effect on item selection, we also explored whether this effect could persist even when other more diagnostic cues (item difficulty and reward value of items) were presented.

In summary, in the current study, we investigated whether font size can influence participants' first item selections during self-regulated learning, providing evidence for the idea that perceptual information plays a key role in higher cognition.

\section{Experiment 1}

In experiment 1 , we manipulated the font size (48 pt vs. $18 \mathrm{pt}$ ). Across each trial, participants were asked to select items for study from a two-item array. We expected that the font size would impact participants' first choice.

Method

Participants A group of 42 students (30 females) with an average age of 20.39 years $(\mathrm{SD}=2.46)$ from Zhejiang Normal University participated in return for partial credit for a course requirement or $¥ 10$.

Design The only within-participant variable was font size (large vs. small).

Materials A set of 36 moderately difficult word pairs were used. Each word consists of two Chinese characters such as 皮 球- 眼睛 (ball-eye). These pairs were taken from a pool of 168 noun pairs. Based on a pretest conducted with an independent sample of 40 participants, who rated the word pairs in terms of difficulty of association of word meanings and familiarity on a 7-point scale, we chose 36 moderately difficult pairs and randomly divided them into two sets of 18 pairs, with one set presented in 18 pt Kai font ${ }^{1}$ and another in 48 pt Kai font. The two sets were equated for difficulty and familiarity ( $p s>$ $0.1)$.

Procedure Participants were tested individually after giving their informed consent. The experiment consisted of two phases: study and test.

Study phase The participants were told they would be asked to study 36 word pairs for an upcoming cued-recall test. The study phase consisted of 18 trials. In each trial, they saw two cue words presented on the screen from left to right, with one presented in $48 \mathrm{pt}$ and the other in $18 \mathrm{pt}$. The frequency of words of each font size type was counterbalanced across left

\footnotetext{
${ }^{1}$ Kai font is one of the most frequently used regular font style in printed materials in China.
} 
and right sides. Participants were told to select either of them for study by pressing the corresponding keys ("q" was used for the left word and " $p$ " for the right one). The whole word pair was then displayed on a new screen. This remained on the screen until the participants hit the enter key, which they were instructed to do after they thought they had memorized the pair. After returning to the previous screen, the participant selected the remaining cue for study.

The trials were presented in one of two possible orders, with one being the reverse of the other. The original order was randomly determined with the constraint that no more than three trials with the same size at the same position could be presented successively.

Test phase Immediately after study, participants completed a test in which participants were prompted to type in the correct target in response to the cue of each pair. These cues were presented in random order.

\section{Results and Discussion}

We examined the order of item selection across trials as a function of font size (48 pt vs. $18 \mathrm{pt}$ ). We present only participants' first choices across trials because these data were most relevant to evaluating our central predictions (cf. Ariel, Al-Harthy, Was, \& Dunlosky, 2011).

Means across participants' proportions of their first choices across trials by font size are presented in Fig. 1. It is evident that participants preferred to select items presented in large font $(\mathrm{M}=.71, \mathrm{SD}=.15)$ more than items presented in small font $(\mathrm{M}=.29, \mathrm{SD}=.15)$, which was confirmed by a paired $t$ test between large and small font, $t(41)=9.14, p<.01, d_{z}=$ 1.41. This effect is consistent with RPL's prediction and also suggests that participants use size of items as a basis for item selection, hence providing evidence that perceptual information impacts control process.

Although self-paced study times and recall performance were not relevant to the purpose of the current study, we also examined these measures for completeness. Mean self-paced study times and proportions of corrected recalled items for each experiment are presented in the Appendix.

\section{Experiment 2}

The results of Experiment 1 supported the hypothesis that font size influences control processes. There is, however, a possible alternative explanation for this effect. It may be that people make their selection based on font size just because it is the only source of variability between items (cf. Rhodes \& Castel, 2008). If so, the effect of font size would be expected to vanish when there was a more valid source of variability. To rule out

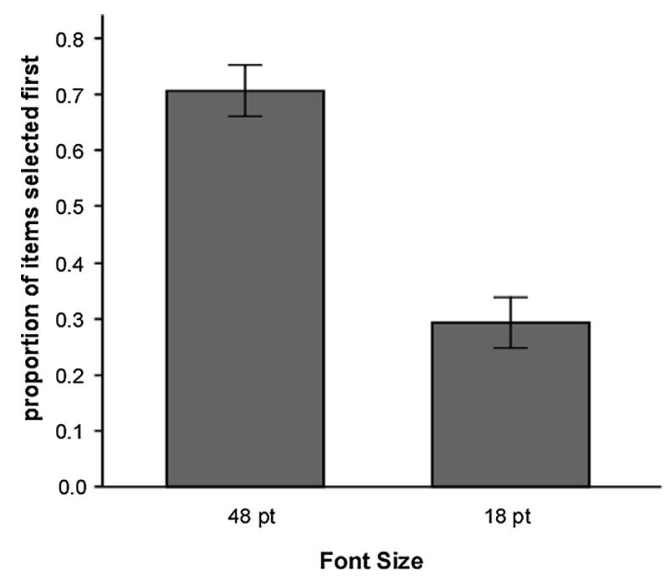

Fig. 1 Proportions of items selected first by font size in experiment 1 . Error bars $95 \%$ confidence intervals

this possibility, in experiment 2 we introduced another source of variability - item difficulty (manipulated by varying associations of word pairs) - which is a kind of variability that strongly influences people's item selection (see Son \& Kornell, 2008, for a review). We examined whether font size would continue to influence participants' item selection when this cue was presented.

\section{Method}

Participants A group of 42 students (28 females) with an average age of $19.52(\mathrm{SD}=2.42)$ from Zhejiang Normal University participated in this study in return for partial credit for a course requirement or $¥ 10$. None of them had participated in experiment 1 .

Design This experiment used a 2 (font size: large vs. small) $\times 2$ (difficulty: difficult vs. easy) within-subjects design.

Materials A set of 48 word pairs were selected from the same pool of 168 word pairs that were used in experiment 1 . Based on the ratings of item difficulty of association of word meanings and familiarity, we chose 24 difficult pairs and 24 easy pairs. Each set of 24 pairs was then randomly divided into two sub-sets of 12 pairs, with one sub-set presented in $18 \mathrm{pt}$ and the other in 48 pt. Thus, we pit item difficulty and font size against each other. There were significant differences in the difficulty ratings between difficult and easy items for large and small font items respectively ( $p s<.01$ ), while the ratings of familiarity were controlled ( $p s>0.1)$.

Procedure The procedure was the same as the one used in Experiment 1, with the only exception being that there were four rather than two cue words on the selecting screen from left to right. In particular, each of the four words represents one type of cues resulted from orthogonal combination of item difficulty and font size. Either the word easy or the word 
difficult, was presented in $33 \mathrm{pt}$ font above each cue word. The frequency of each type of cue words was counterbalanced across four positions.

\section{Results and Discussion}

Means across participants' proportions of their first choices across trials by font size and item difficulty are presented in Fig. 2. A 2 (font size: large vs. small) $\times 2$ (item difficulty: difficult vs. easy) repeated-measures analysis of variance (ANOVA) revealed a significant main effect for size, $F(1,41)$ $=27.42, p<.01, \eta^{2}=.40$, indicating that participants preferred to first select larger items $(\mathrm{M}=.64, \mathrm{SD}=.18)$ than smaller items $(\mathrm{M}=.36, \mathrm{SD}=.18)$. There was also a significant main effect for difficulty, $F(1,41)=4.76, p<.05, \eta^{2}=.10$, indicating that participants preferred to first select easy items $(\mathrm{M}=.61$, $\mathrm{SD}=.33)$ more than difficult items $(\mathrm{M}=.39, \mathrm{SD}=.33)$. These results were in line with the prediction of RPL. There was no interaction between size and difficulty $(F<1)$. The results of experiment 2 showed that participants use font size as a cue to make their item selections even when a more diagnostic cue was presented. These results also suggest that people might use multiple cues when making study item selection. This is in line with findings that people incorporate information about multiple cues when making judgments of learning (e.g., Ariel \& Dunlosky, 2011; Hertzog, Hines, \& Touron, 2013; Serra \& Ariel, 2014; Tauber \& Rhodes, 2012).

\section{Experiment 3}

Experiment 2 showed that the font-size effect on control process continued even when a diagnostic cue of item difficulty was presented. Based on a recent finding that reward value drives item selection more than does item difficulty

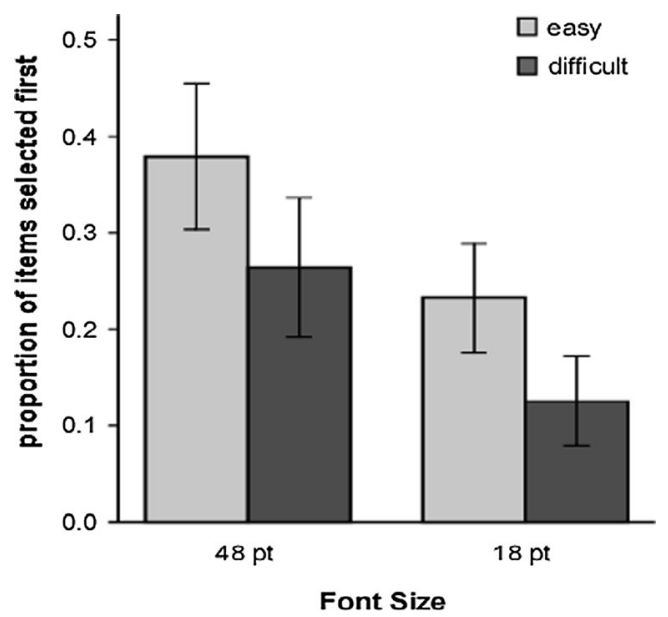

Fig. 2 Proportions of items selected first by font size and difficulty in experiment 2. Error bars $95 \%$ confidence intervals
(Ariel, Dunlosky, \& Bailey, 2009), in experiment 3, we asked whether the font-size effect could continue when reward value of an item (i.e., the number of points earned for successfully remembering an item) was presented.

Method

Participants A group of 38 students (29 females) with an average age of 20.04 (SD $=1.26)$ from Zhejiang Normal University participated in return for partial credit for a course requirement or $¥ 10$. None of them had participated in the previous experiments.

Design A 2 (font size: large vs. small) $\times 2$ (reward value: high vs. low) within-subjects design was used.

Materials A set of 48 moderately difficult word pairs were selected from the same pool of word pairs that used in experiment 1 and 2. Half of them were slated as having a high reward value ( 5 points) and the other half as having a low reward (1 point), with this manipulation of reward value crossed with font size.

Procedure The procedure was identical to Experiment 2, with one exception. In experiment 3 , the reward value (1 point or 5 points, written in $33 \mathrm{pt}$ font) rather than the word easy or difficult was presented above each cue word.

\section{Results and Discussion}

Means across participants' proportions of their first choices across trials by font size and reward value are presented in Fig. 3. A 2 (size: large vs. small) $\times 2$ (reward value: high vs. low) repeated-measures analysis of variance (ANOVA) revealed a significant main effect for font size, $F(1,37)=$ 52.30, $p<.01, \eta^{2}=.59$, indicating people preferred large items $(\mathrm{M}=.73, \mathrm{SD}=.19)$ more than small items $(\mathrm{M}=.27, \mathrm{SD}$ $=.19$ ), consistent with the prediction of RPL. There was also a significant main effect for reward value, $F(1,37)=64.93, p<$ $.01, \eta^{2}=.64$, indicating people preferred high value items (M $=.77, \mathrm{SD}=.21)$ more than low value items $(\mathrm{M}=.23, \mathrm{SD}=$ .21) (Ariel et al, 2009). There was a significant interaction for font size and reward value, $F(1,37)=18.09, p<.01, \eta^{2}=.33$, which reflected that the difference between large and small font was larger when the items were slated as having a high reward value of 5 points $\left(t_{(37)}=6.33, p<.01, d_{z}=1.03\right)$ than when the items were slated as having a low reward value of 1 points $\left(t_{(37)}=3.87, p<.01, d_{z}=.63\right)$. Thus, the interaction did not qualify these main effects. Experiment 3 showed that the influence of font size on people's first selection continued even when reward value of items was presented, consistent with the findings that volume of items influenced participants' JOLs even when the reward value of the items was available 


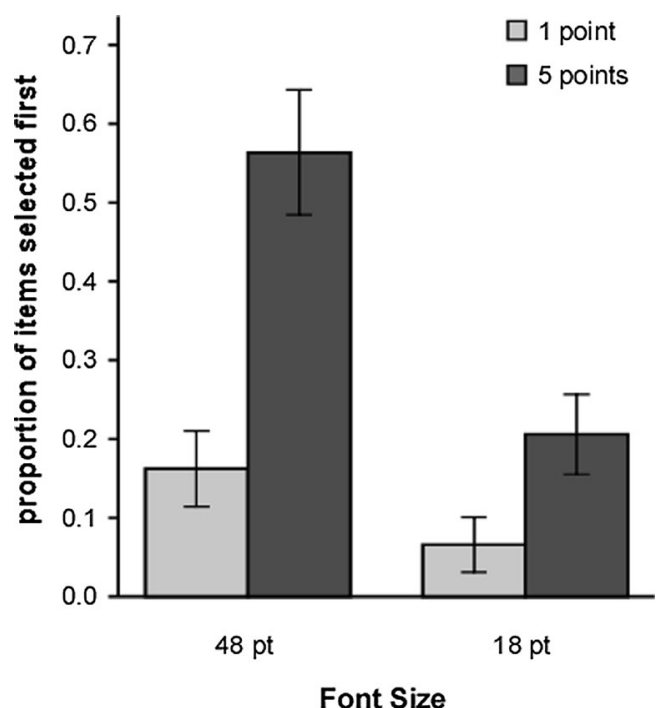

Fig. 3 Proportions of items selected first by font size and reward value in experiment 3. Error bars $95 \%$ confidence intervals

(Foster \& Sahakyan, 2012), suggesting that perceptual information has a robust impact on higher cognition. These results again suggest that control processes might be based on multiple cues.

\section{General discussion}

In the present study, we found that participants preferred to first study large-font items more than small-font items. This effect continued even when diagnostic cues (difficulty and reward value of items) were presented.

Why do people prefer to study large items first? We suggest two possible explanations. The first possibility is that largefont items are processed with greater fluency than small-font items, in line with the prevailing interpretation of font-size effect (e.g., Alter \& Oppenheimer, 2009; Carpenter, Wilford, Kornell, \& Mullaney, 2013; Rhodes \& Castel, 2008). Most of the relevant evidence for this assumption comes from the work of Rhodes and Castel 2008. To test whether processing fluency contribute to the font-size effect, they presented words in a format that alternated between upper and lower case letters (e.g., PiAnO) to make perception disfluent (experiment 6 Rhodes \& Castel 2008). Consequently, this manipulation eliminated the difference between JOLs given for large and small items, suggesting that fluency played a key role in the font-size effect. However, recently, Mueller et al (2014) found that processing fluency plays only a minimal role in and that beliefs about memory (e.g., large words are more memorable) mediated this effect. They also found that the most prevalent beliefs were that the larger words were more memorable because they were distinct or would draw more attention (experiment 3b, Mueller et al. 2014). Since more fluent information is perceived as more distinct (e.g., Whittlesea, 1993) and is more likely to capture attention (e.g., Oppenheimer, 2008), it is plausible that the belief about "large words are more memorable" might be developed based on the fluency engendered by large font size. Thus, it is still reasonable to suggest that the fluency might play a key role in the font-size effect. If this was the case, the greater perceived fluency engendered by large items could also influence participants' item selection. From this point of view, our result is consistent with the prediction of the RPL framework, which argues that when selecting among new items, people prefer to choose easier items (Metcalfe \& Kornell, 2003).

An alternative possibility is that a learner's beliefs that large items are important influences item selection. In the original paper, Rhodes and Castel (2008) also speculated that large items may be perceived as more important than small items. Theoretical support of this idea comes from The Theory of Conceptual Metaphor (e.g., Lakoff \& Johnson,1980), which proposes that people understand abstract concept in terms of concrete experience. For example, people often think about "importance" in terms of "size" by using metaphor IMPORTANT IS BIG (Lakoff \& Johnson, 1999, p. 50), which has been supported by empirical studies (e.g., Guo, Li, Yang, \& Dienes, 2013; Schubert, Waldzus, \& Giessner, 2009). Furthermore, Mueller et al (2014) found that people believe large words to be easier to remember because they are important. This line of evidence, together with the observation that people preferred to select items they think are important for restudy (Ariel et al, 2009), suggests that the metaphorical belief about "large is important" might also bias people's first item selection.

In short, both the fluency account and the metaphorical belief account appear to be plausible. However, we did not directly measure the perceived fluency and importance of the items. Further investigation will be needed to clarify whether the monitoring of fluency or importance influence the control of selection under the framework of "monitoring-affects-control" (Nelson \& Leonesio, 1988).

Moreover, the results of Experiments 2 and 3, showing that font size, difficulty, and reward value all influence participants' item selection, suggest that control processes are based on multiple cues. As mentioned before, this is consistent with the observation that JOLs are influenced by multiple cues (e.g., Ariel \& Dunlosky, 2011; Hertzog; Hertzog, Hines, \& Touron, 2013; Serra \& Ariel, 2014; Tauber \& Rhodes, 2012). This works stemmed from the cue-utilization framework (Koriat, 1997), which posits that people use three types of cues (intrinsic, extrinsic and mnemonic) when making JOLs. However, whether this framework can be extended to control processes remains an open question. Our results shed light on this issue by providing evidence that multiple cues have an impact on participants' item selection. Future research could systematically test the cue-utilization framework for control processes. 
Acknowledgments We thank Dr. Gail D. Heyman for reviewing the manuscript and providing helpful suggestions. This research was supported by National Natural Science Foundation of China (31170999).

\section{Appendix}

Table 1 Mean self-paced study times (in seconds), and mean proportions of items correctly recalled

\begin{tabular}{clll}
\hline & & $\begin{array}{l}\text { Self-paced } \\
\text { study times }\end{array}$ & $\begin{array}{l}\text { Proportions of } \\
\text { items correctly } \\
\text { recalled }\end{array}$ \\
\hline $\begin{array}{c}\text { Experiment } 1 \\
\text { Large font }\end{array}$ & $15.24(11.67)[11.60,18.87]$ & $.71(.18)[.65, .76]$ \\
Small font & $16.27(13.35)[12.11,20.43]$ & $.74(.20)[.68, .80]$ \\
Experiment 2 & & & \\
Large font & Easy & $6.76(5.17)[5.15,8.38]$ & $.89(.10)[.86, .92]$ \\
& Difficult & $16.00(11.12)[12.53,19.47]$ & $.67(.25)[.59, .74]$ \\
Small font & Easy & $5.54(4.39)[4.17,6.91]$ & $.87(.14)[.82, .91]$ \\
& Difficult & $14.86(10.91)[11.46,18.26]$ & $.69(.24)[.62, .76]$ \\
Experiment 3 & & & \\
Large font & 1 point & $9.59(7.71)[7.06,12.13]$ & $.65(.26)[.56, .73]$ \\
& 5 points & $10.69(7.53)[8.21,13.16]$ & $.74(.19)[.68, .80]$ \\
Small font & 1 point & $8.98(7.19)[6.61,11.34]$ & $.68(.18)[.62, .74]$ \\
& 5 points & $10.55(7.78)[7.99,13.11]$ & $.75(.24)[.67, .83]$ \\
\hline
\end{tabular}

Note: means with SDs in parentheses and $95 \%$ confidence interval in square brackets.

\section{References}

Alban, M. W., \& Kelley, C. M. (2013). Embodiment meets metamemory: Weight as a cue for metacognitive judgments. Journal of Experimental Psychology: Learning, Memory, and Cognition, 39(5), 1628-1634.

Alter, A. L., \& Oppenheimer, D. M. (2009). Uniting the tribes of fluency to form a metacognitive nation. Personality and Social Psychology Review, 13, 219-235.

Ariel, R., Al-Harthy, I. S., Was, C. A., \& Dunlosky, J. (2011). Habitual reading biases in the allocation of study time. Psychonomic Bulletin \& Review, 18(5), 1015-1021.

Ariel, R., \& Dunlosky, J. (2011). The sensitivity of judgment-of-learning resolution to past test performance, new learning, and forgetting. Memory \& Cognition, 39(1), 171-184.

Ariel, R., Dunlosky, J., \& Bailey, H. (2009). Agenda-based regulation of study-time allocation: When agendas override item-based monitoring. Journal of Experimental Psychology: General, 138(3), 432-447.

Barsalou, L. W. (2010). Grounded cognition: Past, present, and future. Topics in Cognitive Science, 2(4), 716-724.

Carpenter, S. K., Wilford, M. M., Kornell, N., \& Mullaney, K. M. (2013). Appearances can be deceiving: Instructor fluency increases perceptions of learning without increasing actual learning. Psychonomic Bulletin \& Review, 20(6), 1350-1356.
Dunlosky, J., \& Ariel, R. (2011). The influence of agenda-based and habitual processes on item selection during study. Journal of Experimental Psychology: Learning, Memory, and Cognition, 37(4), 899-912.

Dunlosky, J., \& Hertzog, C. (1998). Training programs to improve learning in later adulthood: Helping older adults educate themselves. In D. J. Hacker, J. Dunlosky, \& A. C. Graesser (Eds.), Metacognition in educational theory and practice (pp. 249-275). Mahwah, NJ: Erlbaum.

Foster, N. L., \& Sahakyan, L. (2012). Metacognition influences itemmethod directed forgetting. Journal of Experimental Psychology: Learning, Memory, and Cognition, 38(5), 1309-1324.

Guo, X., Li, F., Yang, Z., \& Dienes, Z. (2013). Bidirectional transfer between metaphorical related domains in Implicit learning of formmeaning connections. PloS ONE, 8(7), e68100.

Hertzog, C., Hines, J. C., \& Touron, D. R. (2013). Judgments of learning are influenced by multiple cues in addition to memory for past test accuracy. Archives of Scientific Psychology, 1(1), 23-32.

Kleider, H. M., \& Goldinger, S. D. (2004). Illusions of face memory: Clarity breeds familiarity. Journal of Memory and Language, 50(2), 196-211.

Koriat, A. (1997). Monitoring one's own knowledge during study: A cueutilization approach to judgments of learning. Journal of Experimental Psychology: General, 126(4), 349-370.

Kornell, N., Rhodes, M. G., Castel, A. D., \& Tauber, S. K. (2011). The ease-of-processing heuristic and the stability bias dissociating memory, memory beliefs, and memory judgments. Psychological Science, 22(6), 787-794.

Lakoff, G., \& Johnson, M. (1980). Metaphors we live by. Chicago: University of Chicago Press.

Lakoff, G., \& Johnson, M. (1999). Philosophy in the flesh: the embodied mind and its challenge to Western thought. New York: Basic Books.

Metcalfe, J. (2009). Metacognitive judgments and control of study. Current Directions in Psychological Science, 18(3), 159-163.

Metcalfe, J., \& Kornell, N. (2003). The dynamics of learning and allocation of study time to a region of proximal learning. Journal of Experimental Psychology: General, 132(4), 530-542.

Miele, D. B., Finn, B., \& Molden, D. C. (2011). Does easily learned mean easily remembered? It depends on your beliefs about intelligence. Psychological Science, 22(3), 320-324.

Miele, D. B., \& Molden, D. C. (2010). Naive theories of intelligence and the role of processing fluency in perceived comprehension. Journal of Experimental Psychology: General, 139(3), 535-557.

Mueller, M. L., Dunlosky, J., Tauber, S. K., \& Rhodes, M. G. (2014). The font-size effect on judgments of learning: Does it exemplify fluency effects or reflect people's beliefs about memory? Journal of Memory and Language, 70, 1-12.

Nelson, T. O., \& Leonesio, R. J. (1988). Allocation of self-paced study time and the "labor-in-vain effect.". Journal of Experimental Psychology: Learning, Memory, and Cognition, 14(4), 676-686.

Nelson, T. O., \& Narens, L. (1994). Why investigate metacognition. In J. Metcalfe \& A. P. Shimamura (Eds.), Metacognition. Knowing about knowing (pp. 1-25). Cambridge, MA: MIT Press.

Oppenheimer, D. M. (2008). The secret life of fluency. Trends in Cognitive Sciences, 12(6), 237-241.

Rhodes, M. G., \& Castel, A. D. (2008). Memory predictions are influenced by perceptual information: Evidence for metacognitive illusions. Journal of Experimental Psychology: General, 137(4), 615625.

Rhodes, M. G., \& Castel, A. D. (2009). Metacognitive illusions for auditory information: Effects on monitoring and control. Psychonomic Bulletin \& Review, 16(3), 550-554.

Schubert, T. W., Waldzus, S., \& Giessner, S. R. (2009). Control over the association of power and size. Social Cognition, 27(1), 1-19. 
Serra, M. J., \& Ariel, R. (2014). People use the memory for past-test heuristic as an explicit cue for judgments of learning. Memory $\&$ Cognition. doi:10.3758/s13421-014-0431-0

Soderstrom, N. C., \& Rhodes, M. G. (2014). Metacognitive illusions can be reduced by monitoring recollection during study. Journal of Cognitive Psychology, 26(1), 118-126.

Son, L. K., \& Kornell, N. (2008). Research on the allocation of study time: Key studies from 1890 to the present (and beyond). In J. Dunlosky \& R. A. Bjork (Eds.). Handbook of mtamemory and memory (pp. 333-351). New York: Psychology Press.

Susser, J. A., Mulligan, N. W., \& Besken, M. (2013). The effects of list composition and perceptual fluency on judgments of learning (JOLs). Memory \& Cognition, 41(7), 1000-1011.
Tauber, S. K., \& Rhodes, M. G. (2012). Multiple bases for young and older adults' judgments of learning in multitrial learning. Psychology and Aging, 27(2), $474-483$.

Thiede, K. W., \& Dunlosky, J. (1999). Toward a general model of selfregulated study: An analysis of selection of items for study and selfpaced study time. Journal of Experimental Psychology: Learning, Memory, and Cognition, 25(4), 1024-1037.

Whittlesea, B. W. (1993). Illusions of familiarity. Journal of Experimental Psychology: Learning, Memory, and Cognition, 19(6), 12351253.

Wu, L., \& Barsalou, L. W. (2009). Perceptual simulation in conceptual combination: Evidence from property generation. Acta Psychologica, 132(2), 173-189. 